\title{
Characterization of polyethersulfone-polyimide hollow fiber membranes by atomic force microscopy and contact angle goniometery
}

\author{
K.C. Khulbe ${ }^{a, *}$, C. Feng ${ }^{a}$, T. Matsuura ${ }^{a}$, G.C. Kapantaidakis ${ }^{b}$, \\ M. Wessling ${ }^{b}$, G.H. Koops ${ }^{b}$ \\ ${ }^{a}$ Industrial Membrane Research Institute, Department of Chemical Engineering, University of Ottawa, Ottawa, Canada K1N 6 N5 \\ ${ }^{\mathrm{b}}$ Faculty of Chemical Technology, Membrane Technology Group and EMI, University of Twente, P.O. Box 217, \\ 7500 AE, Enschede, The Netherlands
}

Received 20 December 2002; received in revised form 1 May 2003; accepted 7 August 2003

\begin{abstract}
Asymmetric blend polyethersulfone-polyimide (PES-PI) hollow fiber membranes prepared at different air gap and used for gas separation are characterized by atomic force microscopy (inside and out side surfaces) and by measuring the contact angle of out side surface. The outer surface was entirely different than the inner surface, as expected. On the inner surface nodule aggregates were aligned in rows, may be towards the direction of the bore fluid flow. On the outer surface, alignment of nodular aggregates in one direction was not observed. The average mean roughness parameter of the inner surface increased with the increase in the air gap used for the preparation of hollow fiber. On the other hand, it was opposite for the outer surface. From the gas separation experiments it was observed that gas permeation rate increased with the increase in air-gap. An attempt was made to find relationships between the surface morphology observed by AFM and permeability and selectivity of the studied hollow fiber membranes.

From the contact angle measurement it was observed that the contact angle is directly related to the outside surface roughness. A plausible mechanism has been discussed.
\end{abstract}

(C) 2003 Elsevier B.V. All rights reserved.

Keywords: Hollow fiber PES/PI; Blend polymers; Atomic force microscopy; Contact angle

\section{Introduction}

Polymer blends are usually classified as homogeneous or heterogeneous. But in most of the cases and due to thermo dynamical reasons polymeric blends belong to the heterogeneous category. When hollow fibers are prepared from the solution of blended poly-

\footnotetext{
* Corresponding author. Tel.: +1-613-562-5800x6114; fax: +1-613-562-5172.

E-mail address: khulbe@eng.uottawa.ca (K.C. Khulbe).
}

mers and the interaction between the pure polymers is strong enough, then the miscibility is independent of bore fluid chemistry.

The blend of polyethersulfone and polyimide was studied by Liang et al. [1]. It was shown that the blend was to be miscible over the whole range of composition. Ekiner [2] patented polyethersulfone-polyimide membranes for gas separation.

Kapantaidakis and Koops [3] studied the formation and the gas permeation properties of hollow fiber membranes based on PES/PI blends of three different 
compositions (80/20, 50/50 and 20/80 wt.\%). They reported that the air-gap distance in the dry/wet spinning process affects both membrane structure and permeation properties. Scanning electron microscopy (SEM) was used to investigate the morphological characteristics and the structure of asymmetric hollow fibers. They reported that fibers had porous skin layer, loose substructure and high permeation values. Increase in the air-gap length from 1 to $10 \mathrm{~cm}$ during the formation of PES/PI (80/20 wt.\%) hollow fibers, resulted in higher permeation rates for both $\mathrm{CO}_{2}$ and $\mathrm{N}_{2}$. The permeance of $\mathrm{CO}_{2}$ was increased from 57 to $130 \mathrm{GPU}$ while that of $\mathrm{N}_{2}$ increases from 5 to 65 GPU. It was also found that the thickness of the hollow fiber skin layer varied from $1029 \AA$ (air-gap distance of $10 \mathrm{~cm}$ ) to $1198 \AA$ (air-gap distance of $1 \mathrm{~cm}$ ). The PES-PI hollow fibers were further coated with polydimethyl siloxane (PDMS) and the transport properties of coated hollow fibers were studied.

Kesting [4] suggested four superimposed tiers of structure in integrally skinned phase inversion membranes: (1) macromolecules (functionally sub macromolecules, that is displacement of chain segments), (2) nodules (approximately $200 \AA$ in diameter spherical macromolecular aggregates, each of which contains several tens of macromolecules), (3) nodule aggregates (400-1000 ̊ in diameter spherical clumps of nodules), and (4) supernodular aggregates (aggregates of nodule aggregates which constitute the walls of the $0.1-2 \mu \mathrm{m}$ in diameter open cells in the membrane substructure).

In the present paper, we are reporting the morphology of inner surface and the outer surfaces of PES/PI hollow fiber membranes in terms of nodules and nodule aggregates defined by Kesting [4]. The mean roughness parameters of the surfaces were also used for surface characterization. The objective of this work is to find relationship between the surface characterization parameters and the gas permeation properties of hollow fibers.

\section{Experimental}

Hollow fiber blend membranes were prepared by using the commercially available materials polyimide, Matrimid 5218 (Ciba-Geigy) and polyethersulfone Sumikaexcel (Sumitomo) [3,5]. The composition of
PES/PI in blend was 80/20wt.\% and blend composition in NMP was $35 \mathrm{wt} . \%$. The spinning dope was extruded from a spinneret (i.d. $=200 \mu \mathrm{m}$, o.d. $=$ $500 \mu \mathrm{m})$ at $50{ }^{\circ} \mathrm{C}$. The bore fluid $(\mathrm{NMP} /$ water $=$ $80 / 20$ ) was from the central tube of the spinneret to the center of the fiber at a flow rate of $1.12 \mathrm{ml} / \mathrm{min}$. The fiber traveled through an air gap before entering the coagulation bath (water). The air gaps distance was changed from 1 to $10 \mathrm{~cm}$. The humidity of air was maintained at $53 \%$.

The technique for the AFM (Tapping Mode) is described elsewhere [6]. For the inner surface study, the hollow fiber membrane was angle cut by means of a sharp razor blade and AFM images were taken from the inside surface (spoon shape area). The sample was fixed on the magnetic disk by using double side adhesive tape. The laser beam of the AFM was focused on the pre-selected spot of the surface prior to the engagement of the cantilever. Differences in the membrane surface morphology can be expressed in terms of roughness parameters such as the mean roughness. This parameter was measured by AFM itself. The mean roughness is the mean value of surface relative to the central plane, the plane for which the volume enclosed by the image above and below this plane are equal.

The roughness parameter depends on the curvature and size of TM-AFM tip, as well as on the treatment of the captured image (plane fitting, flattering, filtering, etc.). Therefore, the roughness parameter should not be considered as absolute roughness values. However, the same cantilever was used for all AFM images and all the AFM images treated in the same way.

Contact angle measurement was carried out by goniometric ally determining the angle from observation of the three-phase meniscus system described elsewhere in detail [7]. For this purpose, a contact angle goniometer (Rame Hart, Nodel 100), which was modified for hollow fiber was used [7]. Hollow fibers were partially immersed in the test liquid (distilled water). Then meniscus was monitored by the goniometer equipped with an optical camera. Advancing and receding contact angles were measured after the equilibrium condition was reached which gradually increasing and decreasing the level of the test liquid in the container in which hollow fiber was partially immersed achieved. In all cases, contact angle data is reported in terms of advancing contact angle $\left(\theta_{\mathrm{a}}\right)$. 


\section{Results}

\subsection{Atomic force microscopic}

\subsubsection{Inner surface}

Fig. 1a and $\mathrm{b}$ shows the AFM images (scan size $3 \mu \mathrm{m})$ at two different sites of the inner surface of a hollow fiber, when the air-gap was $1 \mathrm{~cm}$. For both images the diameter of nodular aggregates, seen as

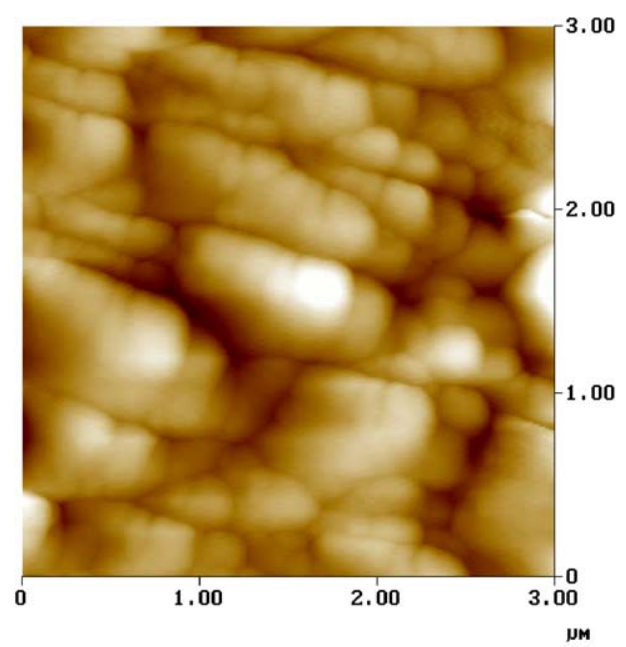

Inside $\quad \mathrm{Ra}=34.144 \mathrm{~nm}$

(a)

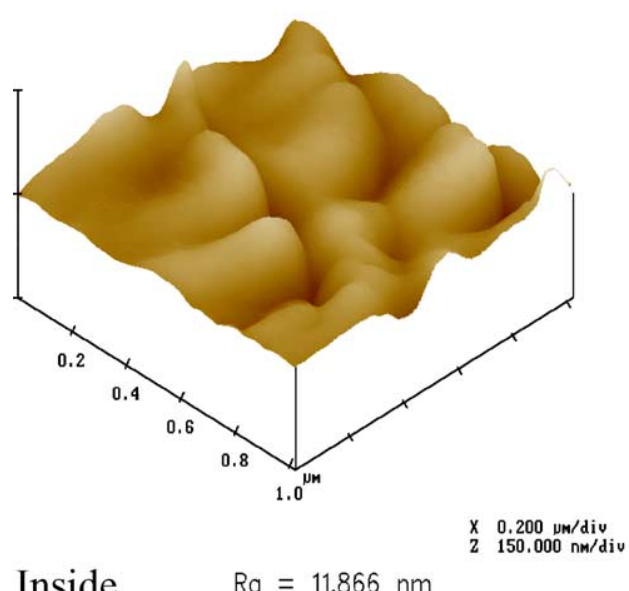

(c) spheres on the images, is measured. The mean, maximum and minimum values listed in Table 1 indicate that there is no meaningful difference in the size of nodular aggregates between two images, although the images look very different. In Fig 1a several nodular aggregates are fused from three to six, while in Fig $1 \mathrm{~b}$ seven to twelve nodular aggregates are aligned in one row. It should be noted that the inside of the hollow fiber was in contact with bore fluid running

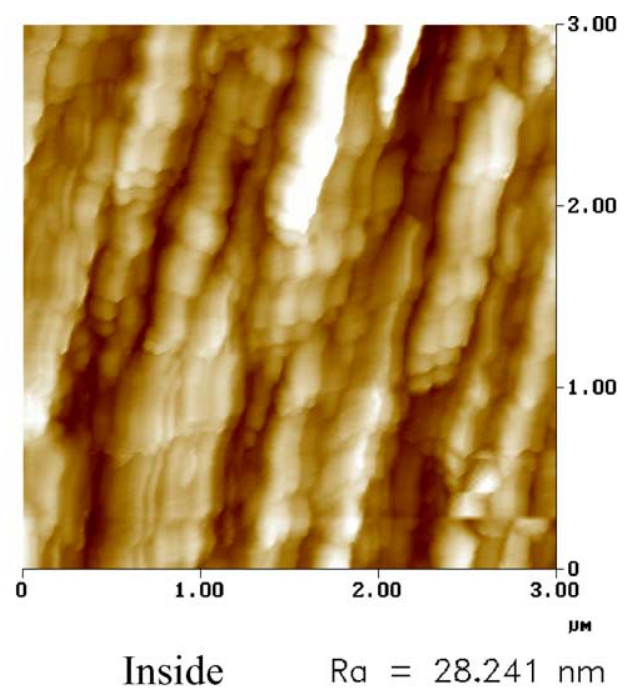

(b)

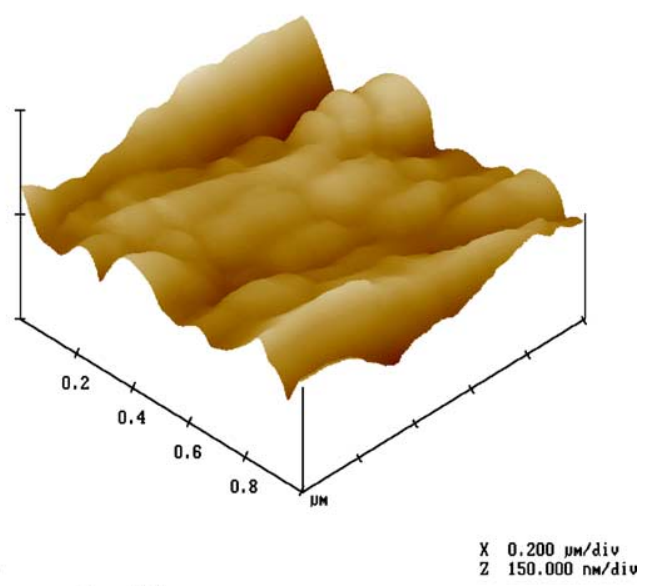

Inside $\quad \mathrm{Ra}=13.656 \mathrm{~nm}$

(d)

Fig. 1. AFM images at four different sites of the inner surface of hollow fiber prepared at $1 \mathrm{~cm}$ air-gap: (a and b) at scan $3 \mu \mathrm{m}$ (top surface) and (c and d) at scan $1 \mu \mathrm{m}$ (3D images). 
Table 1

Mean, maximum and minimum size (diameter) of nodular aggregates at the inner and outer surfaces of hollow fibers when the air gap was 1 and $10 \mathrm{~cm}$

\begin{tabular}{ccccc}
\hline Air-gap (cm) & & $\begin{array}{l}\text { Mean } \\
(\mathrm{nm})\end{array}$ & $\begin{array}{l}\text { Maximum } \\
(\mathrm{nm})\end{array}$ & $\begin{array}{l}\text { Minimum } \\
(\mathrm{nm})\end{array}$ \\
\hline $\begin{array}{c}\text { Inside surface } \\
1\end{array}$ & Fig. 1a & 124 & 188 & 93 \\
& Fig. 1b & 123 & 143 & 95 \\
10 & Fig. 2a & 140 & 170 & 117 \\
& Fig. 2b & 165 & 194 & 120 \\
Out side surface & & & & \\
1 & Fig. 4a & 124 & 186 & 109 \\
& Fig. 4b & 123 & 204 & 94 \\
10 & Fig. 5a & 137 & 172 & 109 \\
& Fig. 5b & 144 & 148 & 94 \\
\hline
\end{tabular}

to the longitudinal direction at high speed. The sheer force working on the surface of the nascent hollow fiber caused nodular aggregates to be aligned to the direction of the bore fluid. Different images observed inFig $1 \mathrm{a}$ and $\mathrm{b}$ indicate that the alignment was not completed when the air-gap was as short as $1 \mathrm{~cm}$. Fig. 1c and $\mathrm{d}$ show the $3 \mathrm{D}$ images of the two sites at $1 \mu \mathrm{m}$ scan.

Fig. 2a and $\mathrm{b}$ show the AFM images at two different sites of the inside surface of the hollow fiber (scan $4 \mu \mathrm{m}$ ) when the air gap was $10 \mathrm{~cm}$. For both images, the diameters of nodular aggregates were measured and the mean, maximum and minimum values are summarized in Table 1. Table 1 shows that there is no meaningful difference in the size of nodular aggregates between the two images. The difference in appearance between Fig. $2 \mathrm{a}$ and $\mathrm{b}$ seems to be much less than the difference between Fig. 1a and b. In both Fig. 2a and $\mathrm{b}$ nodular aggregates are assembled to a number of string-like structure, in which they are aligned in one row. This means that the alignment of nodular aggregates under the strong sheer force was completed when the air-gap was as long as $10 \mathrm{~cm}$. Interestingly, the elongation of the nodular aggregate itself was observed, as evidenced by the (mean length/width) ratio of 1.25. Fig. $2 \mathrm{c}$ and $\mathrm{d}$ show the 3D images of the two sites at $1 \mu \mathrm{m}$ scan. Comparison of Fig. $2 \mathrm{c}$ and $\mathrm{d}$ with Fig. 1c and $d$ indicates that the roughness increased as the air-gap increased. This trend was supported by the measurement of roughness parameters at different air-gaps as shown in Fig. 3a and b, which correspond to scan size of 1 and $3 \mu \mathrm{m}$, respectively.

\subsubsection{Outer surface}

Fig. $4 \mathrm{a}$ and $\mathrm{b}$ show the AFM images (scan $4 \mu \mathrm{m}$ ) at two different sites of the outer surface of a hollow fiber when the air-gap was $1 \mathrm{~cm}$. For both images the diameters of the nodule aggregates were measured and the mean, maximum and minimum values are reported in Table 1. Table 1 shows there is no meaningful difference in sizes of the nodular aggregates between the two images. A noted difference between the inner surface (Figs. 1 and 2) and outer surface (Fig. 4) is that spherical nodules are not aligned to one direction on the outer surface. Fig. $4 \mathrm{c}$ and d show the 3D images of the two sites. Fig. 5a and b show the AFM images (scan $4 \mu \mathrm{m}$ ) at two different sites of the outer surface of a hollow fiber when the air-gap was $10 \mathrm{~cm}$. For both images the diameters of the nodule aggregates were measured and the mean, maximum and minimum values are listed in Table 1. Table shows that there is no meaningful difference between the two images. Unlike inner surfaces (Figs. 1 and 2) there was no alignment of nodule aggregates in one direction, although some pattern is observed in the assemblage of nodular aggregates. Moreover, the area of the dark spots, indicating the troughs on the surface increased as the air gap increased from 1 to $10 \mathrm{~cm}$ (from Figs. 4 to 5). Fig. 5a and $b$ show the 3D images of the two sites. Comparing Fig. $4 c$ and d with Fig. $5 c$ and d, the roughness decreased as the air-gap increased from 1 to $10 \mathrm{~cm}$. The same trend was observed when the roughness parameter was plotted versus air-gap in Fig. 6a and b for the scan sizes of 1 and $4 \mu \mathrm{m}$, respectively.

\subsection{Contact angle}

Fig. 7 shows the contact angle of the outer surface of the PES/PI hollow fiber membranes against air-gap used for the preparation of membranes. From Fig. 7 it seems that the contact angle is decreasing with an increase in air-gap distance.

\subsection{Outer and inner diameters of the hollow fibers}

Table 2 shows the outside diameters and inside diameters of the hollow fibers against the air-gap distance. As the air-gap is increasing both outside and 


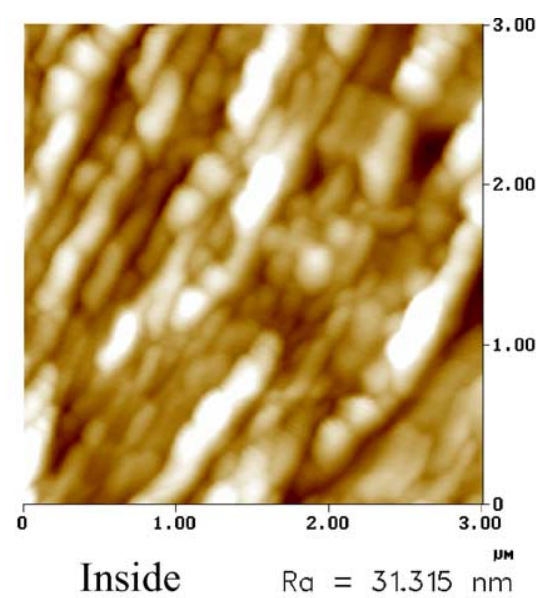

(a)

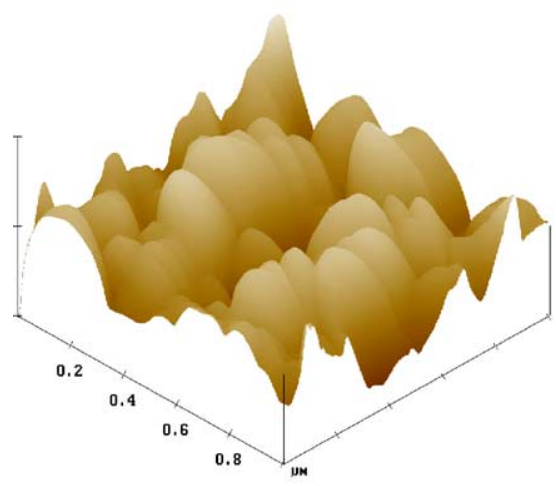

Inside,$R a=31.866 \mathrm{~nm} \quad \begin{array}{ll}\mathrm{x} & 0.200 \mathrm{\mu n} / \mathrm{div} \\ \mathbf{2} & 150.000 \mathrm{~nm} / \mathrm{div}\end{array}$

(c)

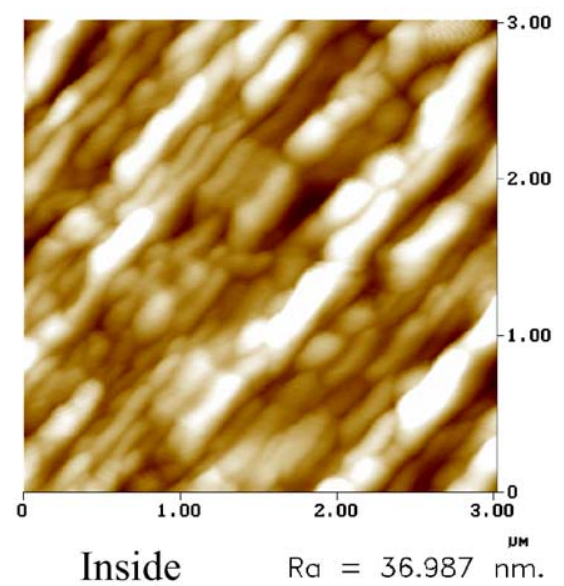

(b)

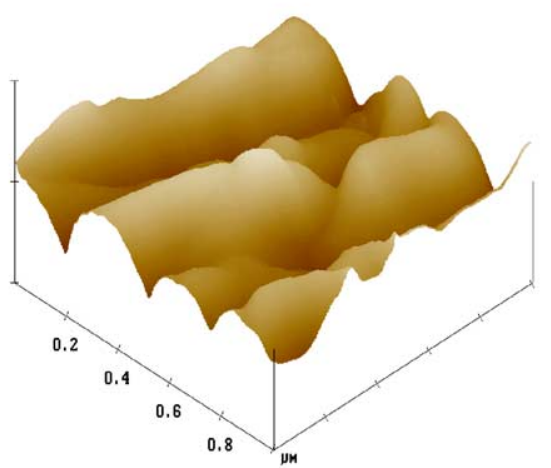

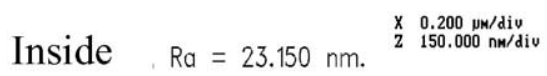

(d)

Fig. 2. AFM images at four different sites of the inner surface of hollow fiber prepared at $10 \mathrm{~cm}$ air-gap: (a and b) at scan $3 \mu \mathrm{m}$ (top surface) and (c and d) at scan $1 \mu \mathrm{m}$ (3D images).

inside diameters increase while the thickness of the hollow fiber decreases. Fig. 8 shows the trend of decreasing of hollow fiber thickness against air-gap distance.

\section{Discussion}

The effect of air-gap on the performance of the hollow fiber membrane and on its morphology is quite

Table 2

Outside and inside diameter and thickness of the PES/PI hollow fiber membrane

\begin{tabular}{llll}
\hline Air-gap $(\mathrm{cm})$ & $\begin{array}{l}\text { Outer diameter } \\
(\mu \mathrm{m})\end{array}$ & $\begin{array}{l}\text { Inner diameter } \\
(\mu \mathrm{m})\end{array}$ & $\begin{array}{l}\text { Thickness of the } \\
\text { membrane }(\mu \mathrm{m})\end{array}$ \\
\hline 1 & 406 & 221 & 92.5 \\
2 & 406 & 223 & 91.5 \\
4 & 408 & 229 & 89.5 \\
6 & 415 & 239 & 88.0 \\
10 & 423 & 244 & 89.5 \\
\hline
\end{tabular}




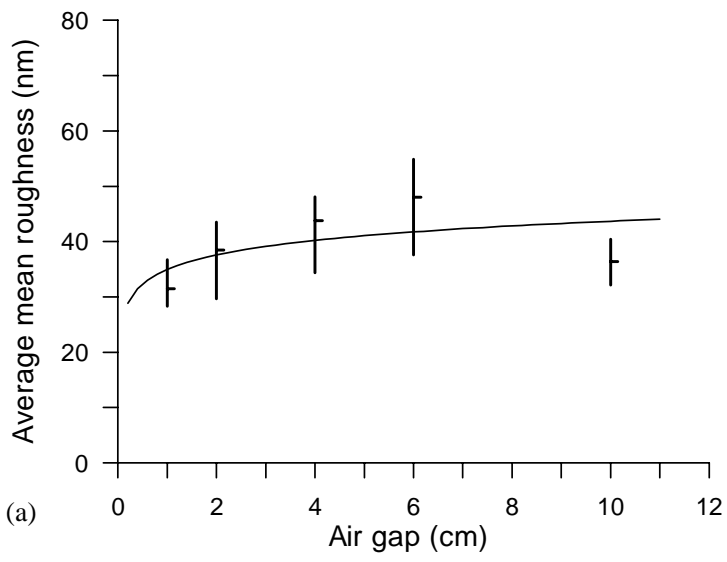

Inside surface mean roughness $(1 \mu \mathrm{m})$

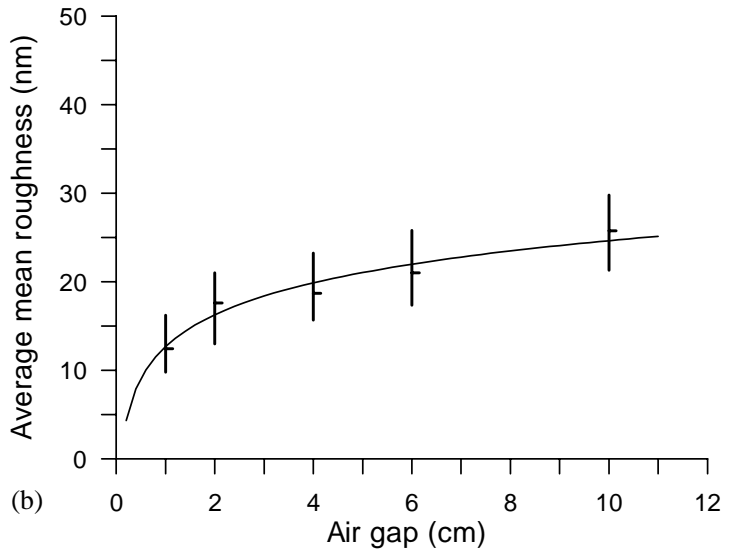

Inside surface mean roughness $(3 \mu \mathrm{m})$

Fig. 3. Mean roughness of the inner surface of hollow fibers against air-gap used for the preparation of hollow fiber membrane: (a) at scan $1 \mu \mathrm{m}$ and (b) at scan $3 \mu \mathrm{m}$.

complex. It depends on the bore fluid rate, polymer concentration in the solution, properties of the solvent used, spin rate, etc. In the present study all the parameters were kept constant except air-gap.

Kapantaidakis and Koops [3] and Kapantaidakis et al. [5] reported that the permeation rate of $\mathrm{CO}_{2}$ and $\mathrm{N}_{2}$ were directly related to the air-gap for these hollow fibers. Khulbe et al. [8] reported that the roughness of the top surface is directly related to the permeation of gases through poly(phenylene oxide) (PPO) membranes. However, this study was focused on flat membranes. Wood [9] studied gas permeation through PPO hollow fibers and reported that the trend for the permeation rate of both methane and $\mathrm{CO}_{2}$ was increase with increasing air-gap distance.

\subsection{Inner surface}

In the earlier study on $\mathrm{CO}_{2}$ and $\mathrm{N}_{2}$ permeation through PES/PI blended hollow fiber membranes coated with PDMS [3], a slight increase in permeation rate was observed with an increase in air-gap. This was attributed to protracted coagulation from the bore side, resulting in a more open structure on the bore side of membrane. It was also postulated that solvent NMP diffused from the bore liquid into the dope, since the bore liquid contained NMP as high as $80 \%$. The increase in air gap resulted in a longer contact time between the nascent fiber and the bore liquid, leading to intrusion of a larger quantity of NMP into the membrane and hence looser structure of polymer on the bore side.

The AFM images support the above view. The nodular aggregates were aligned more to the direction of the bore fluid flow as the air-gap increased. In this process, initially fused nodular aggregates are isolated from each other before being aligned in a row. When the nodular aggregates are reassembled (in a row), they are no longer fused as tightly as before. Hence, the surface roughness increases as nodular aggregates are better aligned to the flow direction with an increase in air-gap. In other words, the nodular aggregates tend to be more loosely packed as the air-gap increases. This is an agreement with a conclusion in the earlier work [3].

\subsection{Outer surface}

Based on a sharp decrease in $\mathrm{CO}_{2} / \mathrm{N}_{2}$ selectivity of uncoated hollow fibers when the air-gap was increased, it was concluded in the earlier study [3] that the skin layer (on the outer surface of the hollow fiber) contained a small fraction of tiny pores and the fraction increased with the air gap. It was further postulated that the increase in porosity was due to the increase in the water content at the skin layer, as the contact time with humid air increased with an air-gap distance. 


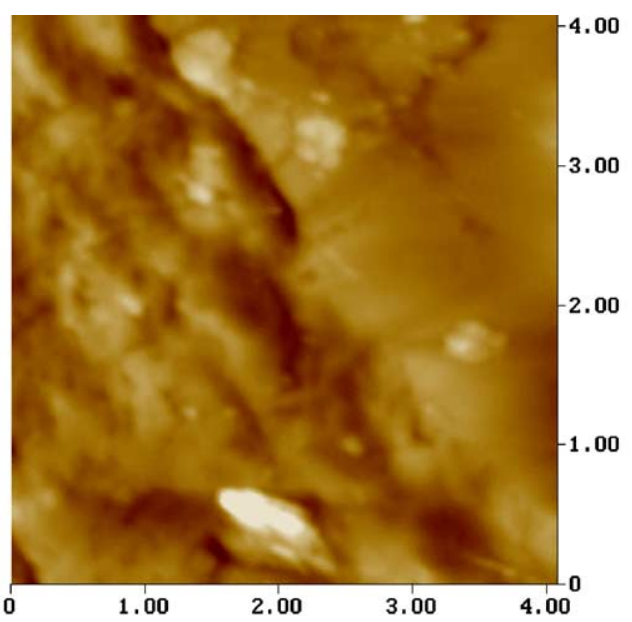

Outside

(a)

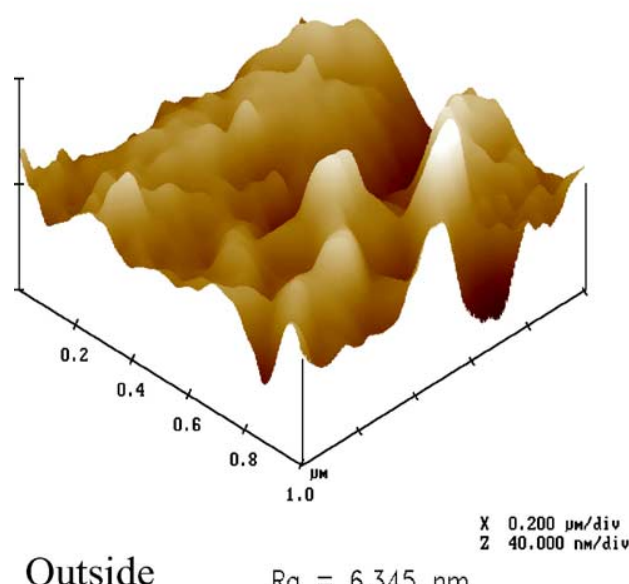

(c)

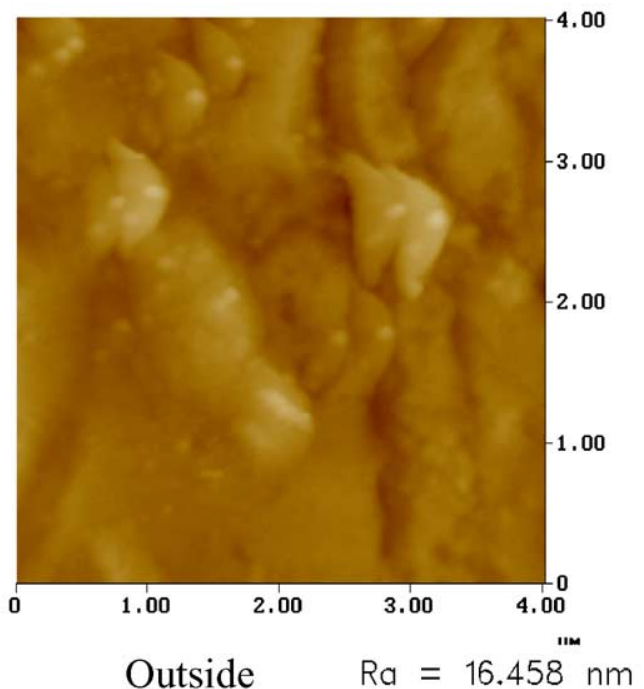

(b)

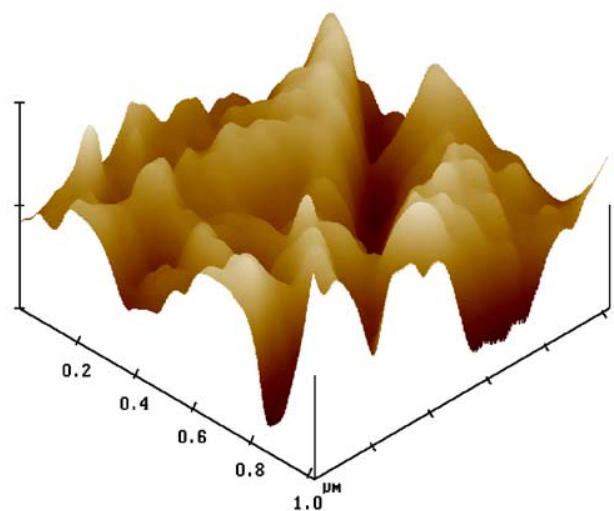

$\begin{array}{ll}X & 0.200 \mathrm{um} / \mathrm{diu} \\ Z & 40.000 \mathrm{~nm} / \mathrm{div}\end{array}$

Outside $\quad \mathrm{Ra}=7.485 \mathrm{~nm}$

(d)

Fig. 4. AFM images at four different sites of the outer surface of hollow fiber prepared at $1 \mathrm{~cm}$ air-gap: (a and b) at scan $4 \mu \mathrm{m}$ (top surface) and (c and d) at scan $1 \mu \mathrm{m}$ (3D images).

The above view is also supported by the AFM images. The casting solution is under stress inside the spinneret. As soon as it comes out of the spinneret, the stress perpendicular to the fiber axis will be released. However, the stress parallel to the axis will remain until the fiber reaches the gelation bath. The release of the stress perpendicular to the axis will result in the expansion of the fiber diameter, while the stress parallel to the axis will elongate the fiber and decrease the fiber diameter.
Looking into Table 2, both outer and inner diameters of the hollow fiber are increasing with the air gap. Therefore, polymer relaxation due to stress release (perpendicular to the axis) seems to dominate while the fiber is traveling through the air-gap. The larger the air-gap, the more relaxed the polymer, and the macromolecules tend to coil and entangle with each other, enhancing the fusion of the nodular aggregates. This is reflected in the decrease of the roughness parameters on the outer surface with an increase 


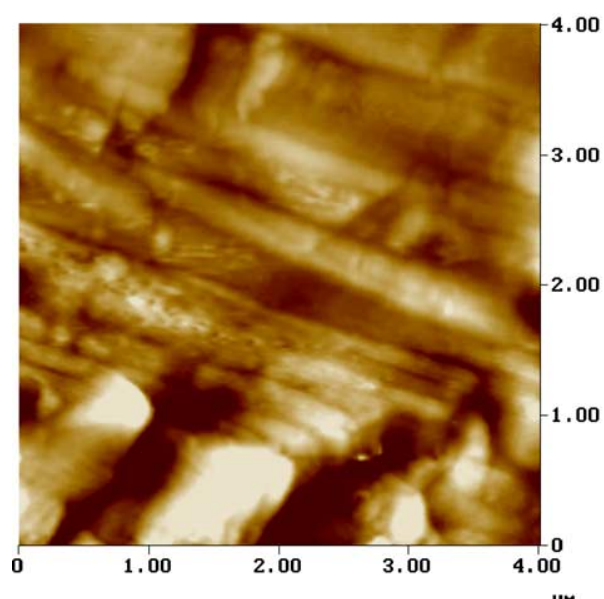

Outside

(a)

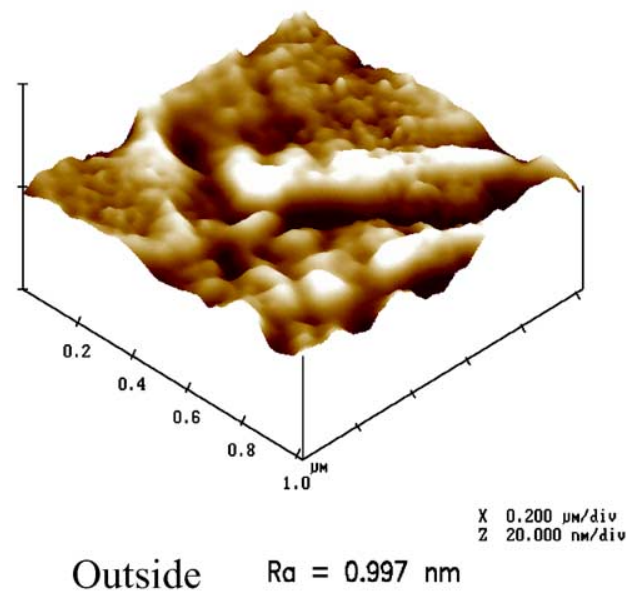

(c)

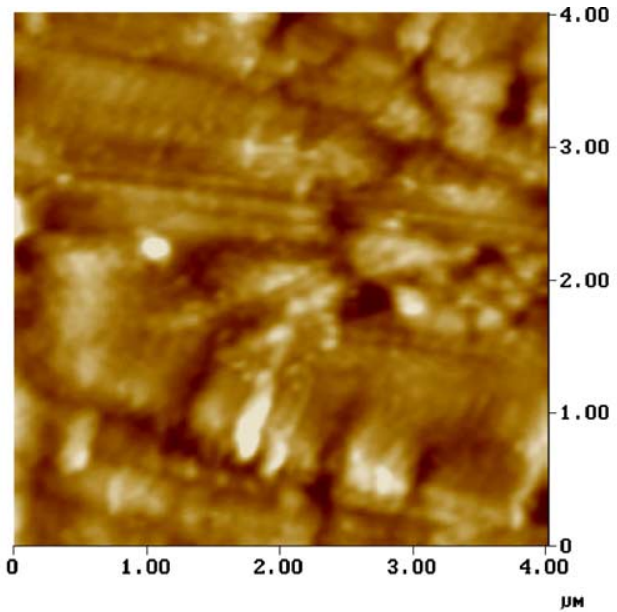

Outside

$\mathrm{Ra}=5.078 \mathrm{~nm}$

(b)

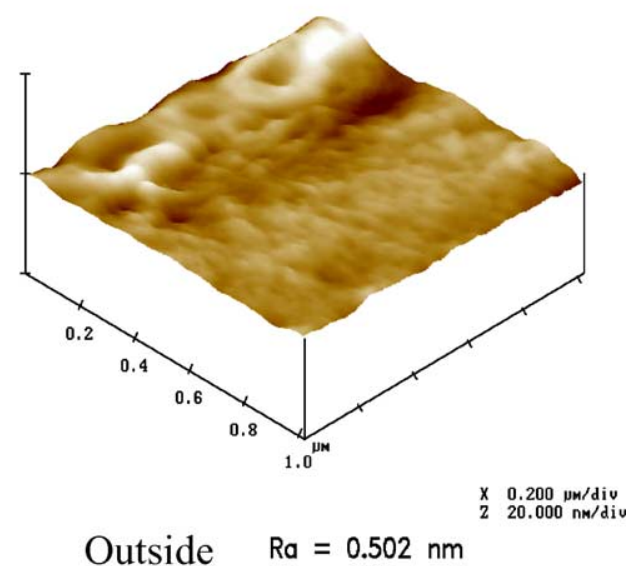

(d)

Fig. 5. AFM images at four different sites of the outer surface of hollow fiber prepared at $10 \mathrm{~cm}$ air-gap: (a and b) at scan $4 \mu \mathrm{m}$ (top surface) and (c and d) at scan $1 \mu \mathrm{m}$ (3D images).

in the air gap. It is hence expected that the selectivity of the membrane will increase in air gap [10]. The experimental results were, however, exactly the opposite. These unexpected results are probably attributable to the increase in porosity, which was caused by an increase in water content in the skin layer, as postulated in the earlier work. This interpretation is supported by the images given in Fig. 5a and b, where relatively large areas of dark spots are observed. Some of these dark spots may be penetrating through the skin layer into the porous sub layer underneath, forming pores that are responsible for the gas leakage.

The present results are also consistent with the results observed by Feng et al. [11] in the study of structure and performance of microporous polyetherimide hollow fiber membranes made by solvent-spinning method. Instead of air-gap they studied the effect of bore liquid flow rate varied between 0.1 and $0.4 \mathrm{ml} / \mathrm{min}$, while keeping the air-gap constant, i.e. $80 \mathrm{~cm}$. The morphology of the surfaces was depending 


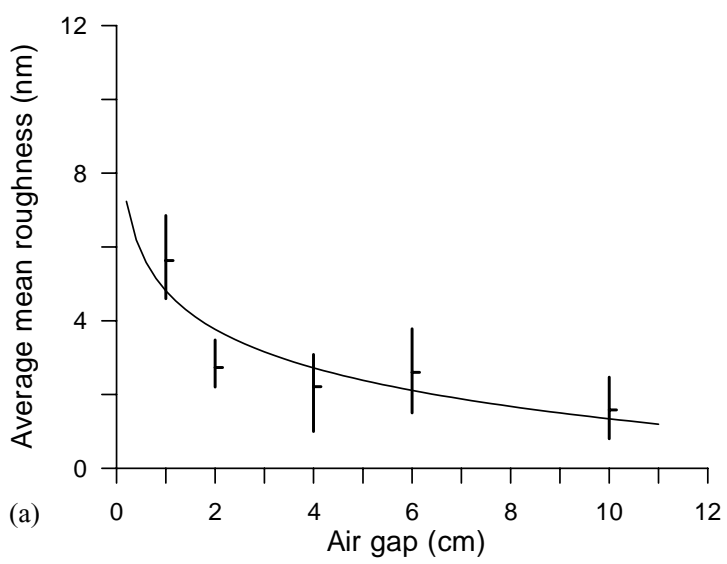

Outside surface mean roughness $(1 \mu \mathrm{m})$

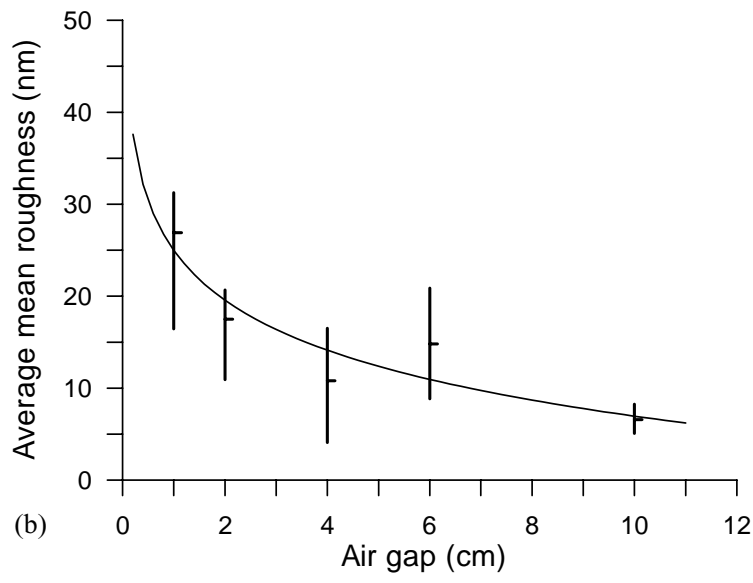

Outside surface mean roughness $(4 \mu \mathrm{m})$

Fig. 6. Mean roughness of outer surface of the hollow fibers against air-gap used for the preparation of hollow fiber membrane: (a) at scan $1 \mu \mathrm{m}$ and (b) at scan $4 \mu \mathrm{m}$.

on the bore fluid rate. Nodular aggregates were strongly aligned in the direction of the bore liquid flow at the inside surface of the hollow fiber, while nodule aggregates were more weakly aligned at the outside surface. Elongation of the nodular aggregate was observed. The roughness of the inside surface increased with an increase in the bore liquid flow rate, while an opposite trend was observed at the outside surface. The surface porosity increased as the bore liquid flow rate increased.

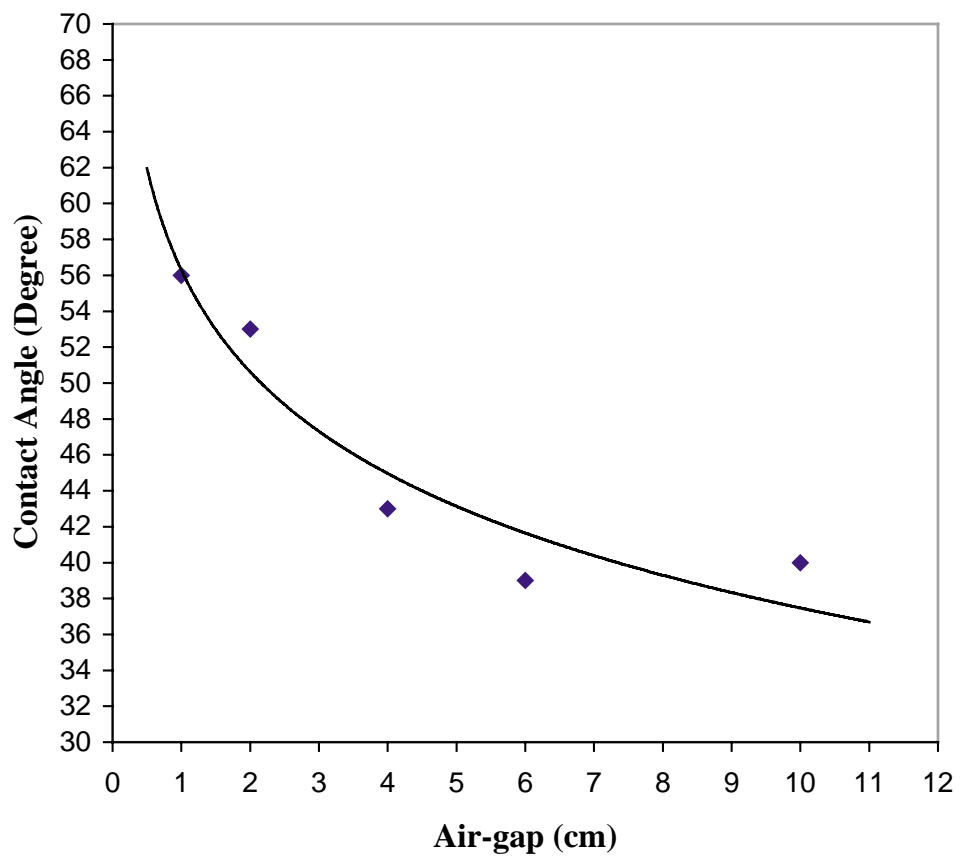

Fig. 7. Effect of air-gap distance on contact angle of the outer surface of the hollow fiber membrane. 


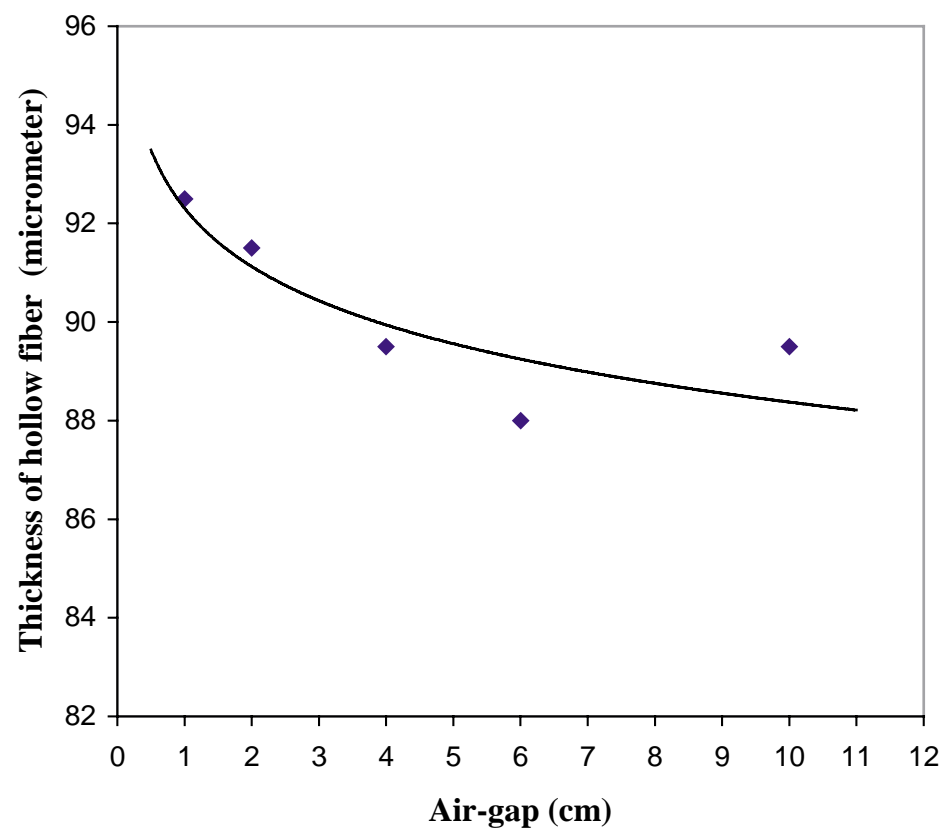

Fig. 8. Effect of air-gap distance on the thickness of the hollow fiber membrane.

Table 1 indicates that on the outer surface, when the air gap distance is $10 \mathrm{~cm}$, the mean size of nodular aggregates is slightly higher than the mean size of nodular aggregates when the air gap is $1 \mathrm{~cm}$. It is reported that the thickness of the active layer of the previous one was less than the second one [3]. Kapantaidakis and Koops [3] found that the thickness of the skin layer of the hollow fiber membranes were 1029 and $1198 \AA$ for the 10 and $1 \mathrm{~cm}$ air-gap distance, respectively. At present due to lack of data no relation could be found between nodular aggregates and the thickness of the active layer.

Fig. 7 shows the contact angle of the outer surface of PES/PI hollow fiber membranes against air gap distance. From Fig. 7 it seems that the contact angle is decrease with the increase in air gap distance. In other words, the contact angle is directly related to the roughness of the surface. Asmanraft [7] reported similar observation in the study of hollow fibers used for dialysis.

Fig. 8 shows the relation between the thicknesses of the PES/PI hollow fiber membranes and air-gap distances. On comparing Figs. 7 and 8, it is interesting to note that the trend of decreasing in both cases, i.e. thickness and contact angle, against air-gap distance is similar.

\section{Conclusions}

From the present study, the following conclusions can be drawn.

1. The morphology of the surfaces (inside and outside) of hollow fibers depends on the air gap during hollow fiber formation.

2. At inner surface, the nodular aggregates were aligned, may be to the direction of bore fluid and formed rows of nodular aggregates. This visual effect was more significant when the air-gap increased. The rows were formed at least by seven to thirteen super nodular aggregate.

3. The mean roughness parameters of the both surfaces depend on the air-gap used to make fiber. The mean roughness parameter of the inner surface increased with the increase of air-gap, while the trend was opposite for the outer surface.

4. Contact angle of the outer surface is directly related to the roughness of the surface. 
5. The inner and outer diameter of the hollow fibers depend on the air-gap.

6. The trend of decreasing of contact angle and the thickness of the hollow fiber membranes against air-gap distances is similar.

\section{References}

[1] K. Liang, J. Grebowicz, E. Valles, F.E. Karasz, W.J. MacKnight, Thermal and rheological properties of miscible polyethersulphone/polyimide blends, J. Polym. Sci., Part B; Pol. Phys. 30 (1992) 465-476.

[2] O.M. Ekiner, Blends of polyethersulfone with aromatic polyimides, polyamides or polyamide-imides and gas separation membranes made there from, European Patent Application 0,648,812 A2 (1994).

[3] G.C. Kapantaidakis, G.H. Koops, High flux polyethersulfone-polyimide blend hollow fiber membranes for gas separation, J. Membr. Sci. 204 (2002) 153-171.

[4] R.E. Kesting, The four tiers of structure in integrally skinned phase inversion membranes and their relevance to the various separation regimes, J. Appl. Polym. Sci. 41 (1990) 27392752.

[5] G.C. Kapantaidakis, G.H. Koops, M. Wessling, Preparation and characterization of gas separation hollow fiber membranes based on polyethersulphone-polyimde miscible blends, Desalination 145 (2002) 353-357.

[6] K.C. Khulbe, B. Kruczek, G. Chowdhury, S. Gagne, T. Matsuura, S.P. Verma, Characterization of membranes prepared from PPO by Raman Scattering and atomic force microscopy, J. Membr. Sci. 111 (1996) 57-70.

[7] M. Asmanrafat, Surface characterization of hollow fiber membranes used in artificial kidney, M.Sc. thesis, University of Ottawa, Ottawa, Canada, January 2002.

[8] K.C. Khulbe, T. Matsuura, G. Lamarche, H.J. Kim, The morphology characterization and performance of dense PPO membranes for gas separation, J. Membr. Sci. 135 (1997) 221-223.

[9] M. Wood, Poly(2,6-dimethyl-11,4-phenylene oxide) hollow fibers for gas separation. Ph.D. thesis, University of Ottawa, Ottawa, Canada, 2002.

[10] K.C. Khulbe, C.Y. Feng, J.M.A. Tan, Polyphenylene Oxide and Modified Poly Polyphenylene Oxide: Gas, Vapor and Liquid Separation, in: G. Chowdhury, B. Kruczek, T. Matsuura, (Eds.), Kulwer Academic Press, London, 2001, p 231.

[11] C.Y. Feng, K.C. Khulbe, G. Chowdhury, T. Matsuura, V.C. Sapkal, Structural and performance study of microporous polyethrimide hollow fiber membranes made by solvent-spinning method, J. Membr. Sci. 189 (2001) 193203. 